\title{
Nature and characteristics of after pain among postnatal mothers admitted in a tertiary care hospital in South India
}

\author{
Smitha P. Namboothiri*, Lekha Viswanath
}

\begin{abstract}
Department of Obstetrics and Gynaecological Nursing, Amrita College of Nursing, Amrita Vishwa Vidyapeetham Health Science Campus, Amrita Institute of Medical Sciences, Kochi-41, Kerala, India
\end{abstract}

Received: 05 July 2016

Accepted: 05 August 2016

\section{*Correspondence:}

Smitha P. Namboothiri,

E-mail: smithapn90@gmail.com

Copyright: ( $)$ the author(s), publisher and licensee Medip Academy. This is an open-access article distributed under the terms of the Creative Commons Attribution Non-Commercial License, which permits unrestricted non-commercial use, distribution, and reproduction in any medium, provided the original work is properly cited.

\section{ABSTRACT}

Background: All postnatal mothers experience pain in some form or the another. Crampy pain in the abdomen known as after pain is a determinant of the uterine involution which is more evident clinically in the first four days postpartum. The present study emerged with a view to study the nature and characteristics of after pain among postnatal mothers at a tertiary care hospital in South India.

Methods: A prospective survey design was used for the study. Quota sampling was used to select 100 postnatal mothers, 50 mothers who had caesarean section and 50 mothers who had vaginal delivery. The mothers were enrolled for the study consecutively in 12-24 hours postpartum till the required sample size was obtained in both the groups. A demographic proforma was designed to collect the background information. The characteristics of after pain were assessed using numerical pain rating scale every 24 hours in the first three postpartum days.

Results: The mean scores of pain on the first three postpartum days among mothers after vaginal delivery were 2.84 , 2.1 and 0.84 respectively and for mothers after caesarean section were $1.6,1.66$ and 0.74 respectively. The scores were greatest on the first postpartum day. No association was found between after pain and variables like mode of delivery and age of the mother. It was found that after pain had an association with with parity on the first and third postpartum days.

Conclusions: Since after pain is an indicator of uterine involution, strict protocols should be established in maternity care units for a comprehensive assessment of after pain.

Keywords: Nature, Characteristics, After pain, Postnatal mother

\section{INTRODUCTION}

The afterpains are painful uterine cramps that occur intermittently for approximately two or three days after childbirth and that results from the contractile efforts of uterus to return to its normal involuted condition. ${ }^{1,2}$

It is common that women experience cramping pain and discomfort following the birth of their baby as the uterus contracts and returns to its pre-pregnancy size. ${ }^{14,15}$ After a normal vaginal delivery, approximately $50 \%$ percent of primiparous mothers and $86 \%$ of multiparous mothers experience afterpain. ${ }^{13}$
The process of uterine involution begins immediately after the placenta expels, when the contraction of the uterine smooth muscles begin, which results in pain. With pregnancy, since there occur hypertrophy of cells, additional cells are laid down during the process of involution which causes much larger uterine size with increase in childbirth. Also, there is significant difference in the uterine involution pattern of mothers with mode of delivery, which was proved by ultrasonographic studies. ${ }^{3,4}$ Thus, it can be concluded that afterpain also varies with mode of delivery and number of childbirths. ${ }^{16,21}$ In the first-time mothers, since the fundus remains firm, uterine tone is good, and the mother does 
not perceive uterine cramping. ${ }^{4}$ With increase in the order of pregnancies, periodic relaxation and vigorous contraction increase, which leads to uncomfortable cramping called afterbirth pains that are prevalent throughout puerperium. After pains are more significantly percieved after childbirths that result in slow return of the uterus to the pre-pregnant stage such as pregnancies with polyhydramnios. Macrosomic babies as well as multiple pregnancies. ${ }^{4,5}$

Breastfeeding is the most commonly reported activity that has been shown to increase the intensities of after pain. During breast feeding, nearly all women commonly report deep pain primarily on lower abdomen, low back, and breast, with associated referred pain in $62 \%$ of them $^{13}$. Following childbirth, the smooth muscles of the areola are contracted to establish breastfeeding due to the action of oxytocin released from the posterior pituitary ${ }^{6}$. At the same time, oxytocin induces contraction of the uterine muscles which leads to crampy pains during breastfeeding. Postpartum caesarean wound pain modulation is unaffected by the endogenous oxytocin released during breastfeeding.

After pain, if prolonged, can lead to neuro-hormonal stress response which further leads to anxiety, insomnia fatigue. ${ }^{7}$ Whatever the form of pain, when prolonged further, increases the chances of depression in the postnatal period. ${ }^{8}$ Also when the pain of uterine contractions intensify with breastfeeding, the mothers often hesitate to feed their babies which even makes them more prone to postpartum depression. ${ }^{9,10}$ Since afterpain is a common problem that affects the physical and mental well-being of mothers, it requires the attention of health care providers for which the present study was undertaken.

\section{METHODS}

A prospective survey approach was used for the study. The study was conducted in the maternity unit of a tertiary care hospital in Kochi, Kerala, South India. Ethical clearance was obtained from the institutional ethical committee prior to data collection. The women who delivered after 35 weeks of gestation were recruited for the study 12-24 hours postpartum. Postnatal mothers who had complications like PPH, puerperal infections and who were not breastfeeding were excluded from the study. Quota sampling technique was used to select 50 mothers who had caesarean section and 50 mothers who had vaginal delivery. The mothers who met the sampling criteria were selected consecutively; in each group till the required sample size was obtained.

After building rapport with the subjects, an informed consent was taken. The mothers were explained that they would be observed for three days and that they could withdraw their participation any time they wanted. The demographic and clinical data were collected using a structured questionnaire and review of client records. For the assessment of after pain, 10-point numerical pain rating scale was used with a minimum score of 0 that indicated no pain and a maximum score of 10 which indicated excruciating pain. Out of these, a score of 1-4 indicated mild pain, 5-7 indicated moderate pain and 8-10 indicated severe pain. The frequency of pain measured how often the mother experienced pain as 'all the time', when moving and 'once only'. First assessment was done between 12-24 hours and subsequent assessment was done every 24 hours thereafter, for the first three postpartum days.

Descriptive and statistical inferences were drawn from the data. Using frequency, percentage and mean, the level and intensity of after pain were expressed. The association between after pain and selected variables was done using Chi-Square Test. Comparison of mean scores of pain between the mothers with vaginal delivery and caesarean section were done using Mann-Whitney test.

\section{RESULTS}

Table 1: Mean scores and standard deviation of after pain among mothers after vaginal delivery and caesarean section.

\begin{tabular}{|lll|l|}
\hline Groups & $\begin{array}{l}\text { Day I } \\
\text { Mean and } \\
\text { S.D }^{\mathbf{a}}\end{array}$ & $\begin{array}{l}\text { Day II } \\
\text { Mean and } \\
\text { S.D }^{\mathbf{a}}\end{array}$ & $\begin{array}{l}\text { Day III } \\
\text { Mean }^{\mathbf{a}}\end{array}$ \\
\hline $\begin{array}{l}\text { Vaginal } \\
\text { delivery } \\
(\mathrm{n}=50)\end{array}$ & $2.84 \pm 3.019$ & $2.1 \pm 2.350$ & $0.84 \pm 1.87$ \\
\hline $\begin{array}{l}\text { Caesarean } \\
\text { section } \\
(\mathrm{n}=50)\end{array}$ & $1.6 \pm 2.634$ & $1.66 \pm 2.715$ & $0.74 \pm 1.78$ \\
\hline $\begin{array}{l}\text { Combined } \\
\text { score of the } \\
\text { groups } \\
(\mathrm{n}=100)\end{array}$ & $2.22 \pm 2.887$ & $1.88 \pm 2.536$ & $0.79 \pm 1.82$ \\
\hline
\end{tabular}

S. $D^{\mathrm{a}}=$ Standard deviation

Table 2: Frequency of perception of after pain by postnatal mothers.

\begin{tabular}{|lll|l|}
\hline Frequency & $\begin{array}{l}\text { Day I } \\
(\mathbf{n}=42)\end{array}$ & $\begin{array}{l}\text { Day II } \\
(\mathbf{n}=\mathbf{4 1})\end{array}$ & $\begin{array}{l}\text { Day III } \\
(\mathbf{n}=\mathbf{1 8})\end{array}$ \\
\hline All the time & 1 & 1 & 0 \\
\hline When moving & 14 & 14 & 5 \\
\hline Intermittently & 27 & 26 & 13 \\
\hline
\end{tabular}

\section{Sample characteristics}

Age: The mean age of mothers was $27.98 \pm 5.322$ years and it ranged from 19 to 40 years. Fourty percentage of the samples were in the age group of 18-25 years. There were 25 mothers who had age in between 26 and 30 years. Twenty six mothers had an age in between 31 and 35 years. Only 9 mothers were in the age group of 36-40 years. 
Table 3: Comparison of mean ranks of abdominal after pain between mothers who underwent caesarean section and vaginal delivery.

\begin{tabular}{|c|c|c|c|c|c|c|}
\hline \multirow[t]{2}{*}{ Day } & \multirow[t]{2}{*}{ Groups } & \multirow[t]{2}{*}{ n } & \multicolumn{2}{|l|}{ After pain } & \multirow{2}{*}{$\begin{array}{l}\text { Mann-Whitney } \\
\text { U }\end{array}$} & \multirow[t]{2}{*}{ p-value } \\
\hline & & & Mean rank & Sum of ranks & & \\
\hline \multirow[t]{2}{*}{ I } & Normal & 50 & 56.21 & 2810.50 & \multirow[t]{2}{*}{964} & \multirow[t]{2}{*}{$0.028^{*}$} \\
\hline & Caesarean & 50 & 44.79 & 2239.50 & & \\
\hline \multirow[t]{2}{*}{ II } & Normal & 50 & 54.16 & 2708 & \multirow[t]{2}{*}{1067} & \multirow[t]{2}{*}{0.156} \\
\hline & Caesarean & 50 & 46.84 & 2342 & & \\
\hline \multirow[t]{2}{*}{ III } & Normal & 50 & 51.28 & 2564 & \multirow[t]{2}{*}{1211} & \multirow[t]{2}{*}{0.688} \\
\hline & Caesarean & 50 & 49.72 & 2486 & & \\
\hline
\end{tabular}

= Significant.

Table 4: Association of abdominal after pain with parity.

\begin{tabular}{|c|c|c|c|c|c|c|c|c|}
\hline \multirow[b]{2}{*}{ Form of pain } & \multirow[b]{2}{*}{ Day } & \multirow[b]{2}{*}{ Intensity of pain } & \multicolumn{4}{|l|}{ Parity } & \multirow[b]{2}{*}{$\chi^{2}$} & \multirow[b]{2}{*}{$\begin{array}{l}\text { p- } \\
\text { value }\end{array}$} \\
\hline & & & $\begin{array}{l}\text { Primi } \\
\mathbf{n}=50 \%\end{array}$ & $\%$ & $\begin{array}{l}\text { Multi } \\
\mathbf{n}=50 \%\end{array}$ & $\%$ & & \\
\hline \multirow{6}{*}{ After pain } & I & Mild & 40 & 80 & 31 & 62 & \multirow[b]{2}{*}{3.934} & \multirow[b]{2}{*}{$0.047^{*}$} \\
\hline & & Severe & 10 & 20 & 19 & 38 & & \\
\hline & II & Mild & 39 & 78 & 39 & 78 & \multirow[b]{2}{*}{0} & \multirow[b]{2}{*}{1} \\
\hline & & Severe & 11 & 22 & 11 & 22 & & \\
\hline & III & Mild & 49 & 98 & 43 & 86 & \multirow[b]{2}{*}{4.891} & \multirow[b]{2}{*}{$0.027^{*}$} \\
\hline & & Severe & 1 & 2 & 7 & 14 & & \\
\hline
\end{tabular}

Degrees of freedom $=1,{ }^{*}=$ Significant.

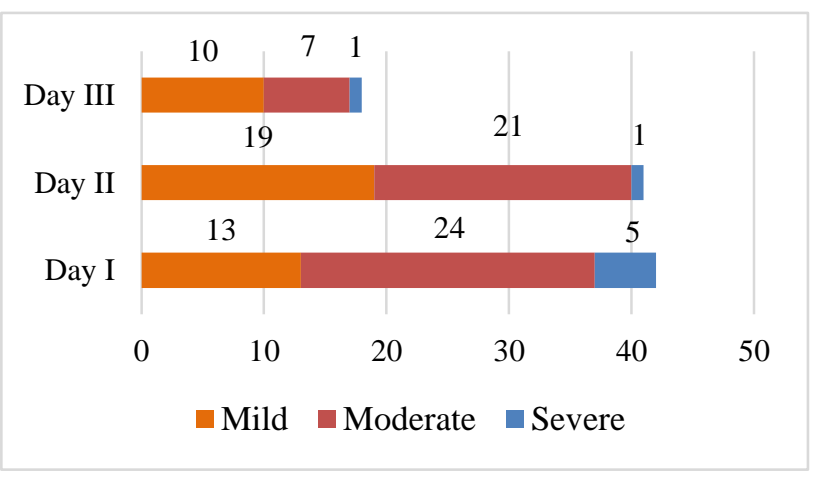

Figure 1: Distribution of mothers based on the intensity of abdominal after pain.

Parity: Most of the mothers were primiparous (50\%). Multiparous mothers were $41 \%$ and grand-multiparous mothers were 9\%. Activity level during pregnancy: Forty-three percentage of the mothers were moderately active during the pregnancy period. Sixteen mothers were sedentary and eight mothers were on bed rest.

\section{Level of after pain}

a) Intensity of after pain: On the first and second postpartum days, 42 percentage of mothers had after pain, whereas on the third postpartum day, 18 mothers reported after pain. Greater number of postnatal mothers experienced severe form of abdominal after pain on Day I postpartum. On the first postpartum day, mild intensity of pain was reported by 13 mothers, moderate pain by 24 mothers and severe intensities of pain by five mothers. But on second postpartum day, 19 mothers perceived mild pain, 21 mothers perceived moderate pain and 1 mother perceived severe pain. This further reduced on third postpartum day with only 10 mothers perceiving mild pain, 7 mothers perceiving moderate pain and one mother reporting severe pain (Figure 1). The mean scores of after pain among mothers who had vaginal delivery on the first three postpartum days were 2.84, 2.1 and 1.44 respectively. Caesarean mothers had a mean score of after pain on the first three postpartum days as 1.6, 1.66 and 0.74. The combined mean scores on the first three postpartum days were $4.44,3.76$ and 1.58 respectively (Table 1).

b) Frequency of after pain: Most mothers intermittently perceive abdominal afterpain on all the three postpartum days. The number of mothers who intermittently perceived pain on all the three postpartum days were 27 , 26 and 13 respectively (Table 2 ).

c) Description of pain: Thirty two mothers on the first and second postpartum day and 14 mothers on the third postpartum day described their pain experience as similar to menstrual cramps. Other descriptions were like throbbing and cramping. Delivery like ache was reported by two mothers on first and second postpartum days. A postnatal mother after vaginal delivery described the pain on her lower abdomen as "I feel a shrill above the umbilicus. Not every time, but intermittently. It increases upon getting up from the bed."

Three mothers on first postpartum day admitted that pain on the lower abdomen was similar to the fetal kicks they perceived during the antenatal period. A mother after vaginal delivery on postpartum day 1 agreed that the pain she felt was like an aching above the umbilicus, which 
she compared with that of the pain that precedes urinary tract infections. Similar experience was verbalised by another mother after vaginal delivery on postpartum day 2. According to a caesarean mother, the after pain was like "I felt that my entire abdomen moves to the sides when I breastfeed my child." Two mothers on day 1 , four mothers on day 2 and 1 mother on day 3 felt the pain to be like "pieces of stone moving inside". They could not express a particular time of the day when the intensity of pain was the greatest.

\section{Comparison of mean scores of after pain among mothers who underwent vaginal delivery and caesarean section}

Mothers after vaginal delivery percieved much severe intensities of after pain than mothers after caesarean section (Table 1). The statistical comparison of mean ranks of abdominal afterpain between mothers who underwent caesarean section and vaginal delivery was done using Mann-Whitney U-test as the data followed a non-nrmal distribution. This showed that the mean ranks of afterpain between mothers who underwent caesarean section and normal vaginal delivery on Postpartum Day I are significant since the p-values were less than 0.05 (Table 3).

\section{Association of after pain with selected variables}

Abdominal after pain was found association with parity and age of the mother. The data revealed that significant association was present between parity and after pain ( $p$ $<0.05$ ) on first and third day postpartum (Table 4).

\section{DISCUSSION}

Preterm childbirth as well as caesarean section leads to lesser degree of uterine involution comparing to mothers after a vaginal delivery at term. ${ }^{3,5,16,21}$ The present study results reveal that compared to the mothers who had delivered at term, the mothers who had preterm childbirth $(n=5)$ had lesser severity of abdominal after pain. This is an important physiological consideration while caring for a mother after preterm child birth. Regular monitoring of the fundal height in preterm mothers would reveal any physiological delay in the involution process. Whenever there is a complaint from the mothers of extensive pain on the abdomen after a preterm caesarean birth even before discharge from the hospital, it needs detailed evaluation as it may be an indicator of delay in the uterine involution.

Studies have revealed that uterine involution is affected by mode of delivery by comparing the symphyso-fundal height between mothers who had vaginal delivery and caesarean section. ${ }^{5}$ This is an indicator of variation in intensities of pain perceived by mothers after vaginal delivery and caesarean section. The present study has compared the intensity of pain between mothers with different modes of delivery. The results demonstrated that more severe forms of after pain are experienced by mothers after vaginal delivery. It was quite perplexing to note that most mothers after caesarean section were not aware of the after pain because of the higher intensities of pain they perceived on the surgical site.

It is found that abdominal after pain increases in childbirths where the uterus is overdistended. ${ }^{13-15}$ In the present study, there was only a single mother who had a twin delivery. But she reported of a pain in the lower abdomen similar to menstrual cramps which is only of mild intensity (pain score $=4$ only on the first day postpartum. The mother further added that the pain became higher when the positions were changed especially for feeding the twins.

Elisabeth Jangsten et al has proved that parity directly affects the intensity of afterpain. ${ }^{11}$ Greater intensities of after pain are expected to be perceived more by multiparous mothers. But the data from the study shows that there is no significant association between abdominal after pain and parity on the second day postpartum whereas the same are significant on the first and third postpartum days. Also more than half of the mothers who had a previous delivery could not remember whether they had the similar experience of pain before.

It is established that breastfeeding increases the intensity of afterpain. ${ }^{12,13,17}$ But most of the mothers $(32,32,13)$ who participated in the study reported that they perceived the pain intermittently and could not say a particular activity that increased the experience of pain. Also, a particular time of the day when the pain was highest in intensity could not be expressed by the mothers. No interference with breastfeeding or child care could be noted due to the presence of after pain. The fact was that, most mothers did not pay much attention to the pain they perceived while feeding their babies since they reported that they had preoccupations with pain during breastfeeding even before childbirth.

A study conducted by Mahin Tafazoli et al proved that movement could be a significant factor in reducing after pain among multiparous women. ${ }^{7}$ Movements help to spread the contractions uniformly throughout the uterus and thus reduce the severity of pain intensity. On the contrary to it, in the present study, nearly half of the mothers experienced higher intensities of pain when moving.

With reference to the description of experience of after pain, in certain studies, women have even reported that they experienced pain, when bed pan was offered and it seemed to be like backpain. ${ }^{11,21}$ In the present study most mothers experienced pain intermittently and they reported it to be similar to that of menstrual cramps. A surprising description of pain was "like stone moving inside". Some mothers could remember that the pain they perceived was similar to the fetal kicks during the later months of pregnancy. 
Even though this is the scenario, abdominal after pain which is a significant form of pain as far as the postpartum physiology is considered, needs supportive care to be provided for the achievement of the prepregnant status among postnatal mothers as soon as possible. We hope that the results of the study trigger interventions to promote high quality services that enhance the health status of mothers.

\section{CONCLUSION}

Since after pain is an indicator of uterine involution, strict protocols should be established in maternity care units for a comprehensive assessment of after pain.

\section{ACKNOWLEDGEMENT}

The authors are grateful to the institutional ethical committee as well as the subjects who participated in the study. All those who provided support for conducting the study are dedicated special thanks.

\section{Funding: No funding sources}

Conflict of interest: None declared

Ethical approval: The study was approved by the Institutional Ethics Committee

\section{REFERENCES}

1. Petrenko N. Postpartum physiology. Nursing care of the Postpartum Woman. Transition to parenthood, 2012. Available at: http://intranet.tdmu.edu.ua/data/kafedra/internal/gine cology $2 /$ classes_stud/en/nurse/bsn/ptn/4/Nursing $\% 2$ 0Care $\% 20$ of $\% 20$ Childbearing\%20Family_Practicum /20.\%20Postpartum\%20physiology.\%20Nursing\%20 care $\% 20$ of $\% 20$ the $\% 20$ Postpartum $\% 20$ Woman.htm. Accessed on 6 June 2016.

2. Sampson KR, Creehan PA. Perinatal nursing. Lippincott Williams; $2^{\text {nd }}$ ed. New York. 2009:445502.

3. Negishi H, Kishida T, Yamada H, Hirayama E, Mikuni M, Fujimoto S. Changes in uterine size after vaginal delivery and cesarean section determined by vaginal sonography in the puerperium. Arch Gynaecol Obstet.1999;263(1-2):13-6.

4. Olayemi O, Omigbodun AA, Obajimi MO, Odukogbe AA, Agunloye AM, Aimakhu CO, et al. Ultrasound assessment of the effect of parity on postpartum uterine involution. J Obstet Gynaecol. 2002;22(4):381-4.

5. Kurmanavicius JFS, Zimmermann R, von Mandach U. Puerperal symphysis fundus distance: normal values. J Perinat Med. 2010;38(2):173-7.
6. Lothian JA. The birth of a breastfeeding baby and mother. J Perinat Educ. 2005;14(1):42-5.

7. Tafazoli M, Khadem M. Assessment of factors affecting after pain in multiparous women delivered at Mashhad 17-Shahrivar Hospital, Mashhad, Iran J Mid W Hea. 2014;2(1):60-5.

8. Eisenach JC, Pan PH, Smiley R, Home PL, Landau R, Houle TT. Severity of acute pain after childbirth, but not type of delivery, predicts persistent pain and postpartum depression pain. 2008;140(1):87-94.

9. Holbrook JH, Haselton MG, Schetter CD, Glynn LM. Does breastfeeding offer protection against maternal depressive symptomatology? A prospective study from pregnancy to 2 years after birth. Arch Womens Ment Health. 2013;16(5):10.

10. Chowdhury R, Sinha B, Sankar MJ, Taneja S, Bhandari N, Rollins N, et al. Breastfeeding and maternal health outcomes: a systematic review and meta-analysis. Acta Padiatr. 2015;104(Suppl 467):96-113.

11. Jangsten E, Strand R, de Freitas EDG, Hellstrom AL, Johansson A, Bergstrom S. Women's perceptions of pain and discomfort after childbirth in Angola. Afr J Reprod Health. 2005;9(3):148-58

12. Stainton MC, Edwards S, Jones B, Switonski C. The Nature of Maternal Postnatal Pain. J Perinat Educ. Spring. 1999;8(2):1-10.

13. Holdcroft A, Snidvongs S, Cason A, Doré CJ, Berkley KJ. Pain and uterine contractions during breast feeding in the immediate post-partum period increase with parity. Pain. 2003;104(3):589-96.

14. Lowdermilk. Perry. Maternity Nusing. Elsevier. $7^{\text {th }}$ ed. NY. 2008:455-56.

15. Murray SS. McKinney ES. Foundations of MaternalNewborn Nursing. $4^{\text {th }}$ ed. NY. 2001:395.

16. Dimitrov A, Nikolov A, Nashar S, Mikhova M, Pavlova E, Krŭsteva K. Puerperal uterine involution according to the method of delivery. Akush Ginecol. 2007;46(9):14-8.

17. Wen L, Hilton G, Carvalho B. The impact of breastfeeding on postpartum pain after vaginal and cesarean delivery. J Clin anesth .2015;27(1):33-8.

18. Murray A, Holdcroft A, Incidence and intensity of Postpartum lower Abdominal pain. BMJ. 1989;1:298.

19. Galli D, Groce P, Chiapparini I, Dedé A. Ultrasonic evaluation of the uterus during puerperium. Minerva Gynaecol.1993;45(10):473-8.

20. Olds. London. Ladewig. Maternal newborn nursing. Prentice Hall. $6^{\text {th }}$ ed: 911

21. Declercq E, Cunningham DK, Johnson C, Sakala C. Mothers' reports of postpartum pain associated with vaginal and cesarean deliveries: results of a national survey. Birth. 2008;35(1):16-24.

Cite this article as: Namboothiri SP, Viswanath L. Nature and characteristics of after pain among postnatal mothers admitted in a tertiary care hospital in South India. Int $\mathbf{J}$ Reprod Contracept Obstet Gynecol 2016;5:3041-5. 